\title{
Albanon
}

Revistë kulturore

\section{Aspekte nga detaria e Ulqinit në shek. XVII-XVIII}

Ardian Muhaj

Pas marrjes së Ulqinit e Tivarit nga osmanët në vitet 1570, tashmë kufiri detar osman në Adriatik shtyhet më në veri duke përfshirë të gjitha trojet bregdetare shqiptare. Kështu fillon ngritja e Ulqinit si qendër detare dhe njëfarë rënie graduale e Vlorës edhe pse pa një lidhje shkakore mes tyre. Duke filluar prej 1571, Ulqini do të shërbejë si një bazë e mirë e detarisë osmane me lidhje të rregullta jo vetëm me Stambollin, por edhe me shtetet detare të Afrikës së Veriut dhe si një bazë ushtarake kundër venecianëve. ${ }^{1}$ Ulqinakët përdornin barka të ndryshme, kryesisht të dimensioneve të vogla e mesatare, por të shpejta si fusta, brigantinë e fregata dhe i përdornin qoftë për të bërë tregti, qoftë për të bërë korsari. ${ }^{2}$

Gjeografia e veprimtarisë së detarëve ulqinakë që në këto raste veprojnë si korsarë, në shekullin XVII shkon duke u zgjeruar vazhdimisht. Më 1624 sulmojnë zonën e Perastit, më 1638 krejt bregun dalmat, më 1654 zonën e Vishit, Korçulës dhe Lastovës, më 1655 zonën e Bokës dhe të Hvarit, më 1659 rrethinat e Zadarit, më 1660 brigjet e Istrias, më 1672 Rijekën dhe Bakrën. Megjithë flotën e organizuar dhe përpjekjet e vazhdueshme për t’i bërë ballë këtij hovi të detarisë ulqinake, Venediku nuk pati rezultate. Mbas përfundimit të luftës së Kretës më 1669, Venediku i shtoi përpjekjet dhe gjithashtu edhe kërkesat ndaj Portës, në mënyrë që të zbuste hovin e madh që kishte marrë korsaria shqiptare. Si rezultat i kësaj, pashait

1 Peter Bartl, "Die Dulcignoten. Piraterie und Handelsschiffahrt im Adriaraum (18. Jahrhundert), f. 19.

2 Ignatije Zloković, "Prilozi za istoriju Ulcinskog gusarstva i brodarstva”, Godišnjak Pomorskog Muzeja u Kotoru, nr. 6, 1957, f. 67; Dinko Franetović, Ulcinj i poslednje pola vijeka njegovih jedrenjaka", Godišnjak Pomorskog Muzeja u Kotoru, nr. 5, 1956, f. 157158. 
të Shkodrës iu dogjën 10 anije ulqinake si paralajmërim për të mos mbështetur dhe urdhëruar korsarët shqiptarë të sulmonin zotërimet dhe anijet venedikase. ${ }^{3}$ Marrëdhëniet paqësore pas luftës së Kretës mes dy fuqive u reflektuan menjëherë në përpjekjet e Stambollit për të ndaluar detarët ulqinakë të sulmonin anije venedikase. Kështu, kur venedikasit kthyen disa robër të rëndësishëm tek osmanët, kryeveziri Ahmed Köprülü u përgjigj me një letër falenderimi ku njëkohësisht premtonte se do të bënte çmos të ndalonte fustat e Shën Maurës dhe Ulqinit që sipas venedikasve vazhdonin të pengonin lundrimin në Adriatik. ${ }^{4}$ Megjithatë, edhe mbas këtyre përpjekjeve, korsaria dhe detaria e shqiptarëve vazhdoi të luante një rol të rëndësishëm në Adriatik deri në mesin e shekullit XVIII. ${ }^{5}$

Nuk kishte se si të ndodhte ndryshe, mbasi pikërisht në këtë kohë, fuqia detare e ulqinakëve e mbështetur në përmirësimin e vazhdueshëm ekonomik të pashallëkut të Shkodrës, u jepte mundësi atyre që të zhvillonin tregti të rregullt të mallrave shqiptare, jo vetëm me zonat e Adriatikut, por edhe me Izmirin e Aleksandrinë. ${ }^{6}$

Mbas vendosjes së marrëveshjes së paqes së Pasarovicit më 1718, osmanët premtuan sërish se do të zhduknin piraterinë ulqinake. Përpjekjet osmane në fakt rezultuan të pafrytshme, mbasi pikërisht në këtë kohë, Pashallëku i Shkodrës, të cilit i përkiste edhe Ulqini, sa po përgatitej të arrinte autonominë nga Porta e Lartë. Përkundrazi pashallarëve shkodranë u duhej që ta ndihmonin dhe t’i jepnin mbështetje sa më të madhe ulqinakëve dhe marinës së tyre, mbasi përbënin një nyje të rëndësishme për tregtinë dhe ekonominë e pashallëkut. ${ }^{7}$ Si pasojë në Ulqin, megjithëse tregtia dalëngadalë shkoi duke marrë përparësi ndaj piraterisë, tregtarët e përdornin piraterinë

3 "La pace rissorta doppo langh'anno d'asprissima guerra, frà la Repub.a Ser.ma, e la Potenza Ottomana, doueua proddur quella quiete, ch'è tanto frata à Dio, et uniforme all'intentione di chi l'hà composta; mà i Maluiuenti di Dolcigno, pietra sempre scandalosa, ed'infesta, auuezzi alle rapine, sconcertauan la base di cosi giusto fondamento. Vigilante però il Prencipe... ottenne dalla Porta s'espedit.ne d'un Capigi, con ordini del Gran s.re d'incendiar quelle fuste e castigare i corsari ... uide abbruggiati dieci di quel legni". Naučna Biblioteka Zadar, Ms. 24384/ 614/ LXXVIII/ I/ I, nr. 2. 18 korrik 1675. P. Bartl, “Die Dulcignoten. Piraterie und Handelsschiffahrt im Adriaraum, f. 21.

4 Letër e 10 qershorit 1674. Setton, Venice, Austria, and the Turks in the Seventeenth Century, 252.

5 Ignatije Zloković, në Pomorska Encilopedija, vëll. 7, Zagreb, 1962, f. 672.

6 Vuk Vinaver, "Pomorstvo Ulcinja u XVIII veku”, Istorijski zapisi, nr. 16, 1963, f. 59-60, 63.

7 V. Vinaver, Pomorstvo Ulcinja u XVIII veku..., f. 56 ; Stavri N. Naçi, Pashallëku i Shkodrës nën sundimin e Bushatlinjve (1757-1796), Tiranë 1964, f. 82-83. 


\section{Albanon}

\section{Revistë kulturore}

edhe si një armë kundër rivalëve të tjerë në tregti. ${ }^{8}$ Rivalët më të afërt për ulqinakët ishin detarët e Perastit. Kështu vetëm në vitet 1720-1755, janë dokumentuar 28 sulme korsare ndaj anijeve nga Perasti. ${ }^{9}$

Fuqia detare ulqinake, e cila padyshim që kishte si bazë të saj zhvillimin e përgjithshëm ekonomik dhe social të zonës së Shkodrës me rrethina, ishte diçka e njohur dhe shqetësim, jo vetëm për detarët dalmatë e italianë, por edhe për ata spanjollë. Më 22 qershor 1734 një tartanë ulqinake u sulmua dhe u kap nga katër anije spanjolle në ujërat e Adriatikut. Anija ulqinake shkonte në drejtim të panairit të Senikalës dhe ishte plot me mallra të tregtarëve shkodranë. Të gjithë tregtarët u zunë rob dhe u dërguan në burgun e Napolit. Një dokument i nënshkruar nga 42 tregtarë ulqinakë e shkodranë, fajësonte direkt indiferencën e venedikasve për këtë dhe pikërisht për këtë arsye i kërcënonte ata. ${ }^{10}$

Megjithatë duhet theksuar se flota ulqinake në thelb ishte flotë që kryente shërbime transporti mallrash për tregtarë të Sanxhakut të Shkodrës e më gjerë, kurse korsaria dhe pirateria vepronin si efekt anësor i këtyre shërbimeve, pavarësisht pretendimit të venecianëve që asnjëherë nuk pushuan së konsideruari cilindo rival detar në Adriatik si pirat. ${ }^{11}$ Në përballjen me marinën venedikase, ulqinakët shpesh ndjeheshin të diskriminuar nga vetë Porta e Lartë e cila lëshonte pe ndaj presionit politik dhe ekonomik të Venedikut. Kështu në 1733 Venecia siguroi dy fermanë sulltanorë përmes ndërhyrjes së Bailiut të Stambollit në të cilët rikonfirmohej një berat sulltanor që ua ndalonte anijeve ulqinake hyrjen në portet e zotërimit venedikas. Kurse dekreti tjetër i jepte një goditje të dyfishtë detarisë ulqinake që duke iu referuar marrëveshjeve të mëhershme iu drejtohej autoriteteve osmane të qyteteve bregdetare që të mos u jepnin strehim kapitenëve ulqinakë që frekuentonin portet e Afrikës Veriore me qëllim ushtrimin e korsarisë. ${ }^{12}$ Vetë komuniteti i detarëve dhe tregtarëve shkodranë e ulqinakë ishte i interesuar për sigurinë e lundrimit dhe të tregtisë në Adriatik, prandaj në fakt ishte vetë kjo bashkësi që reagonte ashpër në raste kur bëhej fjalë për akte piraterie.

8 P. Bartl, “Die Dulcignoten, f. 20; V. Vinaver, Pomorstvo Ulcinja u XVIII veku, f. 55-56.

9 I. Zloković, Prilozi za istoriju Ulcinskog..., f. 67. Maksut Xh. Haxhibrahimi, Detaria e Ulqinit nëpër shekuj, Ulqin, 1994, f. 71-73; Naçi, Pashallëku i Shkodrës, f. 75.

10 Archivio General de Simancas, Estado 5805/59. Peter Bartl, “Die Dulcignoten. Piraterie und Handelsschiffahrt im Adriaraum, f. 26-27.

11 Preto, Venezia e i turchi, f. 224-225.

12 Asv, CSM, 1ํ․, b. 744, 18 gusht 1749; Naçi, Letra të zëv. Konsujve venedikas, vol.1,doc. 99, f. 292-3. 
Kështu në një rast banorët e Shkodrës që vareshin nga tregtia me jashtë i kërkuan pashait të Shkodrës që të digjte shtëpitë e dy shkodranëve që kishin goditur duke e çarë anijen tregtare të kapitenit Comandich, e ankoruar në portin Shirgjit. ${ }^{13}$ Jemi përballë një aplikimi të së drejtës zakonore shqiptare në një rast të marrëdhënieve detare. Duket se arsyeja e një mase kaq të ashpër kishte të bënte me një rast po aq të vështirë siç ishte kapja e 24 tregtarëve shkodranë nga një anije spanjolle gjatë lundrimit drejt Ankonës dhe kërkohej lirimi i tyre. Kjo masë ishte reagim ndaj rasteve të sulmeve të piratëve që trazonin tregtinë e lirë. Kështu kur pirati Haxhi Mustafa nga Ulqini së bashku me të tjerë kapi robër gjatë natës kapitenin dalmat Matteo Bori dhe disa marinarë të një anijeje tregtare venedikase në Bunë, pashai Jusuf Çausholli reagoi shpejt duke bërë të mundur lirimin e tyre, madje duke shkuar vetë në portin e Valdanozit. ${ }^{14}$ Prania e tij duket se kishte të bënte me dyshimin se në këtë aferë ishte përfshirë edhe komandanti ushtark i Ulqinit, si duket i korruptuar nga piratët. Madje u arrit deri aty saqë përmes Bailiut të Stambollit, zëvendës konsulli i mbështetur nga Pashai, kërkoi një urdhër për shkarkimin e tij dhe pezullimin e rrogave të detarëve ulqinakë që bënin transportin e mallrave me Durrësin. ${ }^{15}$ Bashkëpunimi i autoriteteve të Ulqinit me korsarët dokumentohet herë pas here, madje edhe duke bërë një sy qorr ndaj urdhëresave sulltanore apo të autoriteteve më të larta osmane. ${ }^{16}$ Prandaj edhe nuk mungonin rastet e tilla që kërkohej shkarkimi i autoriteteve ulqinake të lidhura me korsarët. Kjo aleancë që mbështetej në interesa të përbashkëta ekonomike interesash mes pushtetit zyrtar dhe forcave jo të rregullta detare, nuk ishte aspak dukuri e kufizuar në brigjet shqiptare apo osmane, por ishte fenomen i përgjithshëm mesdhetar. Shembulli më i qartë në Adriatik ishin autoritetet habsburge që bashkëpunonin me piratët uskokë. ${ }^{17}$

Të shqetësuar për pasojat negative që do të sillte armiqësia e hapur me shkodranët për tregtinë e tyre në Adriatik, venedikasit nga ana e tyre protestojnë tek ambasadori spanjoll Konti i Fuenklarës në Venecia, duke arsyetuar se ky akt ishte një kërcënim ndaj tregtisë së lirë në Adriatik dhe

13 Asv, CSM, 1ํ., b. 744; Naçi, Letra të zëv. Konsujve venedikas, vol. 1, doc. 7, 2 shtator 1734, f. 47.

14 Naçi, Letra të zëv. Konsujve venedikas të Shkodrës (1706-1756),vol. 1, doc. 88, 11 dhjetor, 1748, f. 258.

15 Naçi, Letra të zëv. Konsujve venedikas të Shkodrës,vol. 1, doc. 116, 3 janar 1751, f. 340341.

16 Naçi, Letra të zëv. Konsujve venedikas, vol. 1, doc. 13, 30 shtator 1738, f. 69.

17 Catherine Wendy Bracewell, The Uskoks of Senj: Piracy, Banditry, and Holy War in the Sixteenth-Century Adriatic (Ithaca: Cornell University Press, 1994), 183-184. 
kërkuan që t'u ktheheshin ulqinakëve, anija së bashku me të gjitha mallrat. Spanjollët nuk patën mundësi të rezistonin ndaj këtyre kërkesave, mbasi pak kohë më vonë një anije napolitane që ndodhej nën sundimin spanjoll ishte kapur nga korsarët e Senjit dhe ishte dërguar përt t'u shitur në Venecia. Kështu që si kusht për lirimin e anijes spanjolle, venedikasit vunë lirimin nga ana e spanjollëve të anijes ulqinake. Lidhur me këtë, ambasadori venedikas në Spanjë komunikonte me kryeministrin spanjoll, gjë e cila është edhe dëshmi e rëndësisë që kishte tregtia e shqiptarëve për ekonominë e Adriatikut e madje edhe më tej. ${ }^{18} \mathrm{Nga}$ ky dokument del një e dhënë e rëndësishme, fakti se sa rëndësi kishte mbrojtja e osmanëve për zhvillimin e kësaj tregtie. ${ }^{19} \mathrm{Si}$ pasojë e këtyre ndërhyrjeve deri në nivelet më të larta të shtetit spanjoll, anija ulqinake u lejua të lirohej, por përveç kësaj venedikasit duhej të bënin një deklaratë dhe të angazhoheshin për sigurinë e lundrimit spanjoll në Adriatik. Ajo që ka rëndësi në këtë rast është se fuqia detare e ulqinakëve dhe forca ekonomike e shkodranëve bëheshin shkak për prishjen apo ruajtjen e ekuilibrave mes fuqive të kohës. ${ }^{20}$

Rëndësia e fuqisë detare të shkodranëve dhe ulqinakëve shkonte deri aty sa që në Traktatin e paqes, të tregtisë dhe të lundrimit, të nënshkruar në Stamboll më 7 prill 1740 mes Portës së Lartë dhe Mbretërisë së Napolit e Siçilisë, një nga nenet e këtij traktati shtjellonte posaçërisht çështjen e detarisë ulqinake, duke kërkuar që Porta e Lartë, të mos lejonte që detarët nënshtetas të saj, veçanërisht ulqinakët, por edhe detarët shqiptarë në përgjithësi e të tjerë, gjatë aksioneve të tyre të korsarisë të kryejnë akte luftarake kundër

18 "Prima di tutto dall'ingresso e corso delli suddetti Vascelli la nauigazione, et il commercio sono sommamente perturbati". Archivio General de Simancas, Estado 5805/ 38, 5 gusht 1734. P. Bartl, Die Dulcignoten...

19 "In secondo luogo il bastimento predato ad una nazione, à cui sono troppo facili li motiui de'ricorsi alla Porta, aumenta la grauità delle circostanze», dhe për këtë arsye kërkonte që të ndërhynte edhe zyrtarisht tek mbreti i Spanjës për lirimin e saj «mi commette la Serenis.ma Reppublica, che io esponga à V. E. le sue giuste premure, onde si degni rappresentare alla Maestà del Rè lo stato di questo negozio, affinche dall'equità del medesimo uengano rilasciati gli ordini necessarij à Napoli, onde sia prontamente rilasciata la Tartana predetta». Archivio General de Simancas, Estado 5805/ 38; P. Bartl, Die Dulcignoten...

20 Në një dokument informohej oborri spanjoll se Porta e lartë i kërcënonte venecianët se do t'u jepte leje ulqinakëve që të armatoseshin në korsari, çka do të ishte shkatërrimi i Venedikut. "ponderandome las instancias que a su Baylo ha hecho la Porta sobre este asumpto, con amenazas de dar permiso a los Dulciñotes para armar; y que este es la ruina de este estado, y no menos perjudicial a los subditos de SM Svr. na. AG Simancas, Estado 5805/ 57, 14 janar 1736. P. Bartl, Die Dulcignoten... 
anijeve napolitane. ${ }^{21} \mathrm{Kjo}$ ishte në vazhdën e të atillave traktate, në të cilat çështja e detarisë ulqinake ishte bërë pjesë e pashmangshme e marrëveshjeve ndërkombëtare. Që në marrëveshjen e paqes së Passarowitzit të 1718 që përmbyll Luftën Veneto-Osmane të viteve 1714-18, në mes 13 artikujve ishte edhe një artikull që synonte të ndalonte dhunën në Adriatik nga piratët ulqinakë kundër venedikasve dhe aleatëve të tyre. Artikulli përcaktonte ndalimin e çdo sulmi ndaj anijeve tregtare dhe për më tepër kushdo që nuk e zbaton këtë urdhër do të detyrohet të kthejë çdo mall e gjë që ka marrë dhe në rast se ka shkaktuar dëme apo humbje, vetë ulqinakët do të detyrohen të kompensojnë vlerën e tyre. Pra, shohim se shteti osman nuk i kërcënon detarët ulqinakë me ekzekutime, apo fushata ndëshkimore, por me detyrimin e dëmshpërblimit për dëmet e shkaktuara prej tyre. Kjo ishte në përputhje me zhvillimet e reja në konceptin osman për sovranitetin detar. Që në vitin 1696 kapidan pasha, italiani Mezamorta Hysein Pasha urdhëroi që në ujërat përtej ishujve të Andros, Kos dhe portit të Foça afër Izmirit, nuk duhet ndërmarrë asnjë akt armiqësie ndaj lundrimit tregtar dhe në rast se kjo ndodh, atëherë pala shkaktare duhet të kompensojë të gjitha dëmet e bëra. ${ }^{22}$ Zhvillimi i flotës detare ulqinake dhe i vetë ekonomisë ulqinake gjatë shekullit XVIII u bë gjithnjë e më i madh, aq sa në fundin e këtij shekulli, qyteti që kishte 6 mijë banorë, numëronte rreth vitit 1770 rreth 150 anije, ${ }^{23}$ me të cilat zhvillonte tregtinë jo vetëm në zonën e gadishullit Apenin dhe atij Ballkanik, por edhe jashtë tyre, si Gjibraltari, Izmiri, Aleksandria. Madje ka pasur edhe një pjesë të këtyre anijeve që e kanë kaluar Gjibraltarin, duke mbërritur deri në Kongo, ku janë marrë me tregtinë e skllevërve. ${ }^{24}$

Veçori e kësaj periudhe është se që nga mesi i shekullit XVIII detaria ulqinake do të jetë më shumë tregtare sesa luftarake. Intensiteti i aksioneve

21 «XVII. La sublime Porte défendra rigoureusement qu'aucun de ses Sujets, spécialement ceux de dulcigno, de l'albanie ou autres, allant en course, commettent aucune hostilité contre notre bâtimens \& vaisseaux». Jaques Savary des Bruslons, Dictionnaire universel de commerce, d'histoire naturelle, \& des arts \& mettiers. Contenant tout ce qui concerne le commerce qui se fait dans les quatre parties du monde, par terre, par mer, de proche en proche, \& par des voyages de lonfg cours, tant en gros qu'en détail, sixieme edition, tome quatrieme, A geneve, Chez les Frerese Cramer\& Claude Philibert, 1750, kol. 529.

22 Michael Talbot, Protecting the Mediterranean: Ottoman legal and naval responses to maritime violence in the eighteenth century, University of Greenwich.

23 V. Vinaver, Pomorstvo Ulcinja u XVIII veku..., f. 66. Kurse teksti i historisë së Malit të Zi e jep popullsinë e Ulqinit në fillim të shek. XVIII sipas vlerësimit të konsullit venedikas të Durrësit, prej 10 mijë banorësh, me një flotë prej rreth 4 mijë detarësh. Istorija Crne Goree. Od početka XVI do kraja XVIII vijeka, tom I, knj. 3. Titograd, 1975, f. 529.

24 I. Zloković, në Pomorska Encilopedija, vëll. 7, vep. cit. 


\section{Albanon}

\section{Revistë kulturore}

të korsarisë dhe të piraterisë do të shkojë duke rënë. Megjithatë nuk merr fund, pasi në këtë kohë vërehet një bashkëpunim i ulqinakëve me detarët e Tripolit. ${ }^{25}$ Përmes këtij bashkëpunimi, anijet ulqinake kryenin aksione korsarie edhe përtej Adriatikut akoma edhe në këtë kohë. Një dokument i viti 1761, që është një raport i ambasadorit të mbretërisë së Dy Siçilive në Stamboll, njofton se piratët ulqinakë akoma vazhdonin të sulmonin në zonën e Siçilisë. ${ }^{26}$ Në këto shndërrime ndikuan edhe masat energjike të ndërmarra nga sundimtarët bushatlinj të cilët nuk ishin të interesuar për vazhdimin e mëtejshëm të korsarisë, por të tregtisë. Kështu një ndër masat e para që ndërmori Mehmet Pashë Bushatliu sapo mori pushtetin, ishte kapja dhe djegia e anijes korsare me 34 rrema të reisit ulqinak Hajdar Pirei, që shërbente nën flamurin e Tripolit. Që prej asaj kohe thuhet se nuk u lejua më që anijet shkodrane apo ulqinake të shkonin në Tripoli, ${ }^{27}$ por nuk duket të jetë rasti. Duket se inkuadrimi i anijeve ulqinake në flotën tregtare të Pashallëkut zgjati dy-tri dekada.

Ajo që duhet theksuar dhe që i dallon detarinë e brigjeve shqiptare është se pavarësisht angazhimit sporadik në korsari, thelbin e kësaj detarie e ka përbërë aktiviteti tregtar dhe tranportues. Nuk ka raprezalje të ngjashme me ato që ndodhin në portet e Berberisë nga anijet europiane duke filluar nga shek. XVII. ${ }^{28}$

25 "Poco fà vi erano in questi mari quattro Corsari Dolcignotti con Bandiera di Tripoli... intanto la comparsa sua nell'Arcipelago farà bensi, che li presenti Corsari si ritirino altroue; mà appena egli avrà voltate le spalle à quelle acque che le infesteranno come prima." AG Simancas, Estado 5875/73. 13 qershor 1761; P. Bartl, “Die Dulcignoten..., f. 25.

«sulli Corsari Dolcignotti, che infestano questi mari». AG Simancas, Estado 5875/73, po aty.

27 Shqipëria e Veriut në shek. XVIII. (Letra të zëv. Konsujve venedikas të Shkodrës), përgatitur për botim nga Stravri N. Naçi, vëll. II (1757-1802), Akademia e Shkencave e RPSH, Instituti i Historisë, Tiranë, 1975, dok. nr. 1, f. 37. datë 14 gusht 1757..

28 E. Rouard de Card, Traités de la France avec les pays de l'Afrique du Nord (Algérie, Tunisie,T ripolitaine, Maroc), Paris, 1906, f. 428. 